\title{
Chemical content of unrecorded distilled alcohol (bai jiu) from rural central China: Analysis and public health risk
}

\author{
Ian M. Newman ${ }^{1}$, Ling Qian², Niran Tamrakar ${ }^{1}$, Yonghua Feng ${ }^{1}$, and Ganrong Xu ${ }^{3}$ \\ ${ }^{1}$ Nebraska Prevention Center for Alcohol and Drug Abuse, Department of Educational Psychology, University of Nebraska-Lincoln, Lincoln, NE, \\ United States \\ ${ }^{2}$ Department of Guidance \& Training, Chinese Center for Health Education, Beijing, China \\ ${ }^{3}$ Key Laboratory of Industrial Biotechnology, Jiangnan University, Wuxi, China
}

\begin{abstract}
Aims: To test 47 samples of locally distilled unrecorded beverage alcohol (bai jiu) obtained in rural central China.

Methods: Alcohol samples purchased from home-based makers or from small village shops were analyzed for ethanol, methanol, acetaldehyde, ethyl acetate, six higher alcohols, arsenic, cadmium, and lead. Results were judged against the standards for these compounds set by the AMPHORA Project.

Findings: Ethanol concentrations ranged from 38.7\% to 63.7\% (mean 50.4\%). Methanol and methyl acetate detected in all samples did not exceed the Alcohol Measures for Public Health Research Alliance (AMPHORA) limits. Acetaldehyde was present in all samples, with three samples exceeding the AMPHORA limit by a small amount. Lead was found in $57.4 \%$ of the samples with one sample exceeding the AMPHORA limit; cadmium was found in $89.4 \%$ of the samples with two exceeding the AMPHORA limit. Arsenic was found in $46.8 \%$ of the samples with none exceeding the AMPHORA limit.

Conclusions: The three samples that exceeded AMPHORA limits for cadmium or lead are of concern in terms of the potential of long-term exposure for local people who regularly consume locally made bai jiu. The main health concern from bai jiu appears to be the risk associated with high ethanol concentration-the same health concern as for recorded, commercially produced spirits.
\end{abstract}

\section{Introduction}

Unrecorded alcohol makes up about 25\% (World Health Organization [WHO], 2014) to 30\% (Tang et al., 2013) of total per capita adult consumption of alcohol in China. Because unrecorded alcohol is produced, sold, and consumed outside of regulatory channels, there is a concern about the threat to public health resulting from the consumption of potentially adulterated and contaminated alcohol (Lachenmeier, Sarsh, \& Rehm, 2009; Rehm, Kanteres, \& Lachenmeier, 2010; WHO, 2014). When people die from drinking contaminated unrecorded alcohol, it generates much media attention, but the contribution of these deaths to total alcohol-related mortality is probably less than 1\% (Rehm et al., 2014). A systematic review of worldwide literature on the consumption and toxicology of unrecorded alcohol concluded that "the major public health threat of unrecorded alcohol is clearly related to ethanol" (Rehm et al., 2014). This review also noted that "[t]here is a relative dearth of information on China"; therefore, it is not possible to conclude what, if any, health risks other than ethanol are present in unrecorded alcohol in China.

Correspondence: Ian M. Newman, University of Nebraska-Lincoln, PO Box 880345, Lincoln, NE 68588-0345 USA, Tel. +1 402-472-3844, Fax. +1 402-472-8319, E-mail: inewman1@unl.edu

Financial support: This work was supported by The Buffalo Beach Company with funds received from the International Center on Alcohol Policies, now known as the International Alliance for Responsible Drinking. ICAP/IARD is funded by several of the world's largest alcohol producers. ICAP played no role in the management of the study, the study design, the identification of the field settings, sample collection, analysis of the samples, or the writing of this article. Declaration of interest: Prior to 2014 Ian Newman was a member of the Research Advisory Committee of the International Center for Alcohol Policies (ICAP), Washington, D.C. Prior to 2014 he received fees and travel support to attend meetings sponsored or co-sponsored by ICAP. Prior to 2013 Ian Newman consulted for the National Health Education Institute, Chinese CDC, Chinese Center for Health Education (CCHE). In the past five years, he has received University of Nebraska employment-related funding from the U.S. Department of Education, the Nebraska Department of Health and Human Services, the Nebraska Department of Roads/Nebraska Office of Highway Safety. As American deputy director of the American Exchange Center at Xi'an Jiaotong University, Newman received funds from the US State Department and the University of Nebraska. Ian Newman owns an equity interest in The Buffalo Beach Company (Lincoln, Nebraska) and has received consulting fees from The Buffalo Beach Company for independent research on indigenous alcohol use and traffic safety. Ling Qian was a member of an International Center for Alcohol Policies advisory committee and has received fees and travel support to attend and to speak at meetings sponsored or co-sponsored by ICAP, now known as the International Alliance for Responsible Drinking (IARD). She has received research support from ICAP/IARD. She received support from The Buffalo Beach Company for independent research on indigenous alcohol use. Her regular salary was paid by the Chinese government through the Chinese Center for Health Education. Niran Tamrakar, Yonghua Feng, and Ganrong Xu have no competing interest to report.

Keywords: unrecorded alcohol, artisanal alcohol, spirits, China, noncommercial alcohol, bai jiu, 白酒, traditional alcohol, homemade alcohol, homebrew 
A search of the China National Knowledge Inventory for reports on the analysis of Chinese unrecorded distilled spirits produced no other studies.

This paper describes the chemical content of 47 samples of bai jiu (白酒, literally “white spirits”), a popular, traditional, and widely consumed type of alcohol in China. Bai jiu is made from grain, typically rice, buckwheat, or corn, that is fermented then distilled. It is best described as "traditional" alcohol, as the production methods are indigenous to China and have been used for hundreds of years. It can also be considered an artisanal alcohol.

Both recorded and unrecorded brands of bai jiu are readily available and frequently imbibed in most of rural China. Interviews with 207 drinkers living in this same rural region of central China (Qian, Newman, Xiong, \& Feng, 2015) indicated $77.8 \%$ of male drinkers and $48.0 \%$ of female drinkers drank unrecorded bai jiu. There is no standard of container size or serving size for unrecorded bai jiu, and the strength of bai jiu varies, making it difficult to estimate individual consumption of unrecorded alcohol in terms of pure alcohol.

Important social occasions ranging from weddings to business deals require drinking bai jiu. Also, many rural people believe that drinking bai jiu daily prevents sickness and relieves fatigue. Seventy percent of rural Chinese drinkers interviewed by Qian et al. (2015) said they drank daily. Bai jiu is culturally important; therefore, most rural villages have at least one local bai jiu maker and/or seller to supply the need (Qian et al., 2015). The production of homemade, unrecorded bai jiu ranges from small-scale home-based production for family and village consumption to larger-scale factories selling to a wider area. The focus of this study is alcohol samples obtained directly from home-based makers or from small village shops that sold locally made bai jiu. The production and sale of unrecorded bai jiu is legal in the area where this study occurred. Regulation of local bai jiu makers ranges from none at all to makers having a small business license or a permit from a public health agency. Making bai jiu is a respected skill as well as a source of income in rural areas. Qian et al. (2015) reported on the observation of smallscale production methods of bai jiu and noted that since makers, sellers, and drinkers usually know one another, there is likely little risk of intentional or unintentional contamination. However, their report does not rule out a risk of some kinds of contamination related to environment, skill of the distiller, or the state of his equipment. Qian et al. (2015) further noted that the unrecorded bai jiu was generally less expensive than recorded bai jiu, which might contribute to heavier consumption.

\section{Method}

\section{Sampling}

Researchers traveled to towns and villages in rural Xianning (Hubei Province) that were known to have local alcohol makers and small shops selling locally made bai jiu. Typically they found several types of bai jiu for sale, differing in price, strength, age, and grain used, with olderaged and higher-ethanol bai jiu costing more. At each site, researchers purchased two or three samples of one jin (500 $\mathrm{ml}$ ) of locally produced, unrecorded bai jiu in the mid-price range. Half of the samples were purchased directly from bai jiu makers and half were purchased at small village shops. There are no restrictions (hours, days, or minimum age) on selling unrecorded bai jiu. Samples were collected in clean sample bottles provided by the researcher, sealed, and refrigerated prior to analysis.

\section{Chemical Analysis}

The description of methods used for analysis is provided in Appendix A. Quantitative determination of volatile components was done by Gas Chromatography with a flame-ionization detector. Nitrogen was the carrier gas. Graphite furnace atomic absorption spectroscopy was used to determine the concentration of heavy metals (arsenic, cadmium, and lead). The concentration of ethanol was determined using an oenometer (alcoholometer). Volatile compounds contained in the samples are expressed in the unit of $\mathrm{g} / \mathrm{hl}$ of pure alcohol (pa), whereas volatile metal components are reported in $\mu \mathrm{g} / \mathrm{L}$.

\section{Chemical Safety Evaluation}

Evaluating the results of this analysis is difficult because of the lack of uniform international standards for maximum safe levels of these compounds. We used the Alcohol Measures for Public Health Research Alliance (AMPHORA) cut points as our reference. AMPHORA is a program of the European Commission that investigated many unexplored areas of alcohol consumption and alcohol-related harm in Europe. In the process, AMPHORA scientists established standards for assessing the chemical safety of unrecorded alcohol (Lachenmeier et al., 2011).

\section{Result}

The result of the analysis of the samples is shown in Table 1. The ethanol in these samples, reported as percent alcohol by volume (ABV), ranged from $38.7 \%$ to $63.7 \%$. (2.1\% had ABV < 39.9\%; $46.8 \%$ had ABV from $40.0 \%$ to 49.9\%; $49.0 \%$ had ABV from $50.0 \%$ to $59.9 \%$; and $2.1 \%$ had ABV > 60.0\%). Methanol was detected in all our samples with concentrations ranging from $0.3 \mathrm{~g} / \mathrm{hl}$ pa to 2.4 $\mathrm{g} / \mathrm{hl}$ pa. Acetaldehyde was present in all samples ranging from $2.4 \mathrm{~g} / \mathrm{hl}$ pa to $59.5 \mathrm{~g} / \mathrm{hl}$ pa. All samples contained detectable amounts of ethyl acetate. Concentrations ranged from $0.9 \mathrm{~g} / \mathrm{hl}$ pa to $45.0 \mathrm{~g} / \mathrm{hl}$ pa. All samples were tested for six higher alcohols. The levels were: 1-propanol, 2.3$149.4 \mathrm{~g} / \mathrm{hl} \mathrm{pa;} 1$-butanol, 0.0-0.6 g/hl pa; 2-butanol, 0.1$46.2 \mathrm{~g} / \mathrm{hl} \mathrm{pa}$; isobutanol, 0.4-12.8 g/hl pa; isoamyl alcohol, $0.2-21.3 \mathrm{~g} / \mathrm{hl} \mathrm{pa}$; and 1-hexanol, 0.0-1.2 g/hl pa. The sum of the six higher alcohols in our samples ranged from 4.7 $\mathrm{g} / \mathrm{hl}$ pa to $201.1 \mathrm{~g} / \mathrm{hl}$ pa. 
Table 1

Chemical composition of samples of traditional bai jiu from rural central China

\begin{tabular}{|c|c|c|c|c|c|c|c|c|c|c|c|}
\hline \multirow[b]{2}{*}{ Sample } & \multirow[b]{2}{*}{$\begin{array}{c}\text { Ethanol } \\
\text { (ABV\%) }\end{array}$} & \multicolumn{10}{|c|}{$\mathrm{g} / \mathrm{hl}$ of pure alcohol (pa) } \\
\hline & & Methanol $^{\mathrm{b}}$ & Acetaldehyde $^{\mathrm{b}}$ & $\begin{array}{c}\text { Ethyl } \\
\text { acetate }^{\text {b }}\end{array}$ & $\begin{array}{c}1- \\
\text { propanol }^{\mathrm{b}}\end{array}$ & $\begin{array}{c}1- \\
\text { butanol }^{\mathrm{b}, \mathrm{c}}\end{array}$ & $\begin{array}{c}2- \\
\text { butanol }^{\mathrm{b}}\end{array}$ & Isobutanol $^{\mathrm{b}}$ & $\begin{array}{l}\text { Isoamyl } \\
\text { alcohol }^{\text {b }}\end{array}$ & $\begin{array}{c}1- \\
\text { hexanol }^{\mathrm{b}, \mathrm{c}}\end{array}$ & $\begin{array}{l}\text { Sum of higher } \\
\text { alcohols }\end{array}$ \\
\hline 1 & 63.7 & 1.9 & 29.5 & 9.9 & 32.2 & 0.2 & 19.4 & 8.8 & 21.3 & 0.1 & 82.1 \\
\hline 2 & 52.9 & 0.4 & 5.1 & 3.9 & 3.2 & 0.0 & 1.3 & 2.3 & 4.7 & 0.0 & 11.5 \\
\hline 3 & 47.6 & 0.4 & 3.7 & 3.1 & 3.4 & 0.0 & 1.3 & 1.7 & 3.7 & 0.0 & 10.1 \\
\hline 4 & 59.7 & 0.5 & 4.7 & 2.8 & 3.5 & 0.1 & 1.4 & 1.6 & 3.1 & 0.0 & 9.6 \\
\hline 5 & 47.6 & 0.3 & 2.4 & 3.3 & 3.3 & 0.0 & 1.2 & 1.1 & 2.4 & 0.0 & 8.1 \\
\hline 6 & 49.6 & 0.7 & 4.5 & 4.6 & 6.1 & 0.1 & 1.9 & 1.3 & 2.9 & 0.1 & 12.5 \\
\hline 7 & 57.4 & 0.5 & 3.5 & 5.3 & 5.3 & 0.1 & 1.9 & 1.2 & 2.4 & 0.0 & 10.8 \\
\hline 8 & 54.2 & 1.0 & 11.9 & 9.5 & 16.0 & 0.2 & 8.3 & 4.0 & 8.4 & 0.1 & 37.0 \\
\hline 9 & 56.3 & 0.8 & 7.8 & 6.4 & 14.1 & 0.2 & 6.8 & 3.6 & 7.8 & 0.1 & 32.7 \\
\hline 10 & 51.0 & 1.0 & 35.0 & 7.4 & 14.1 & 0.4 & 1.3 & 9.5 & 14.6 & 0.2 & 40.1 \\
\hline 11 & 48.7 & 1.7 & 55.9 & 6.0 & 7.8 & 0.3 & 1.6 & 9.5 & 15.2 & 0.1 & 34.4 \\
\hline 12 & 51.1 & 1.1 & 42.7 & 5.0 & 6.8 & 0.2 & 1.0 & 12.8 & 17.4 & 0.1 & 38.3 \\
\hline 13 & 50.4 & 0.7 & 35.5 & 5.3 & 4.8 & 0.1 & 0.5 & 10.9 & 14.3 & 0.1 & 30.6 \\
\hline 14 & 52.8 & 0.9 & 59.5 & 7.2 & 4.2 & 0.1 & 0.9 & 2.4 & 6.2 & 0.2 & 13.9 \\
\hline 15 & 48.9 & 0.6 & 9.1 & 8.2 & 3.0 & 0.1 & 0.5 & 1.9 & 4.3 & 0.2 & 9.8 \\
\hline 16 & 49.7 & 1.0 & 48.0 & 9.9 & 5.3 & 0.1 & 2.1 & 4.1 & 10.1 & 0.2 & 21.8 \\
\hline 17 & 38.7 & 1.7 & 10.7 & 2.2 & 2.8 & 0.0 & 0.4 & 1.1 & 2.8 & 0.1 & 7.2 \\
\hline 18 & 51.2 & 0.8 & 12.1 & 6.0 & 4.5 & 0.1 & 1.1 & 2.1 & 4.4 & 0.0 & 12.1 \\
\hline 19 & 48.2 & 0.5 & 26.7 & 6.6 & 3.9 & 0.1 & 1.8 & 3.4 & 8.8 & 0.1 & 18.0 \\
\hline 20 & 49.2 & 1.0 & 11.1 & 6.3 & 9.8 & 0.3 & 1.8 & 5.9 & 11.2 & 0.6 & 29.6 \\
\hline 21 & 50.4 & 0.7 & 11.4 & 7.6 & 3.1 & 0.0 & 0.7 & 1.7 & 4.1 & 0.1 & 9.7 \\
\hline 22 & 53.7 & 1.4 & 10.1 & 7.4 & 9.8 & 0.1 & 3.7 & 3.1 & 5.7 & 0.4 & 22.9 \\
\hline 23 & 49.4 & 1.1 & 18.8 & 8.3 & 10.0 & 0.1 & 3.0 & 5.6 & 11.3 & 0.6 & 30.7 \\
\hline 24 & 48.3 & 0.5 & 11.8 & 2.4 & 2.9 & 0.1 & 0.9 & 1.8 & 3.3 & 0.1 & 9.1 \\
\hline 25 & 49.6 & 0.6 & 11.2 & 2.9 & 3.7 & 0.1 & 0.9 & 2.1 & 3.9 & 0.1 & 10.7 \\
\hline 26 & 54.0 & 0.8 & 25.6 & 8.0 & 9.8 & 0.2 & 5.4 & 1.5 & 3.1 & 0.1 & 20.1 \\
\hline 27 & 52.8 & 0.8 & 54.4 & 10.2 & 10.6 & 0.4 & 8.4 & 2.0 & 4.1 & 0.2 & 25.8 \\
\hline 28 & 46.2 & 0.5 & 34.8 & 6.9 & 4.6 & 0.1 & 2.0 & 1.6 & 3.9 & 0.1 & 12.3 \\
\hline 29 & 53.5 & 1.8 & 32.8 & 8.6 & 7.6 & 0.3 & 1.3 & 8.6 & 13.7 & 0.3 & 31.6 \\
\hline 30 & 50.5 & 1.0 & 5.3 & 2.9 & 6.4 & 0.3 & 0.9 & 1.6 & 2.4 & 0.1 & 11.7 \\
\hline 31 & 52.7 & 1.0 & 11.0 & 3.7 & 4.6 & 0.1 & 0.8 & 1.5 & 2.5 & 0.1 & 9.5 \\
\hline 32 & 49.8 & 1.4 & 9.8 & 4.4 & 5.3 & 0.1 & 1.2 & 1.3 & 2.8 & 0.1 & 10.7 \\
\hline 33 & 49.0 & 1.1 & 15.5 & 45.0 & 149.4 & 0.1 & 33.2 & 5.4 & 12.1 & 0.9 & 201.1 \\
\hline 34 & 49.0 & 0.6 & 13.1 & 10.9 & 56.1 & 0.2 & 46.2 & 7.1 & 14.1 & 1.2 & 124.9 \\
\hline 35 & 47.9 & 0.5 & 15.0 & 13.1 & 65.1 & 0.1 & 7.8 & 4.3 & 10.4 & 0.5 & 88.2 \\
\hline 36 & 50.5 & 1.2 & 18.9 & 19.4 & 114.5 & 0.1 & 31.9 & 7.5 & 14.1 & 1.0 & 169.1 \\
\hline 37 & 44.4 & 2.4 & 7.3 & 0.9 & 3.9 & 0.0 & 0.1 & 0.4 & 0.2 & 0.1 & 4.7 \\
\hline 38 & 51.3 & 1.6 & 18.2 & 3.7 & 4.2 & 0.1 & 0.7 & 1.1 & 2.6 & 0.4 & 9.1 \\
\hline 39 & 56.2 & 0.5 & 12.7 & 11.2 & 56.2 & 0.1 & 6.7 & 3.7 & 8.9 & 0.4 & 76.0 \\
\hline 40 & 49.6 & 0.6 & 16.0 & 2.4 & 2.3 & 0.1 & 0.1 & 2.8 & 4.3 & 0.1 & 9.6 \\
\hline 41 & 48.3 & 0.8 & 9.3 & 17.2 & 55.8 & 0.1 & 8.0 & 3.4 & 7.7 & 0.5 & 75.4 \\
\hline 42 & 50.9 & 1.0 & 33.6 & 18.4 & 21.1 & 0.2 & 15.9 & 4.8 & 9.9 & 0.5 & 52.3 \\
\hline
\end{tabular}


62 Ian M. Newman et al.

\begin{tabular}{|c|c|c|c|c|c|c|c|c|c|c|c|}
\hline \multirow[b]{2}{*}{ Sample } & \multirow[b]{2}{*}{$\begin{array}{c}\text { Ethanol } \\
\text { (ABV\%) }\end{array}$} & \multicolumn{10}{|c|}{$\mathrm{g} / \mathrm{hl}$ of pure alcohol $(\mathrm{pa})^{\mathrm{a}}$} \\
\hline & & Methanol $^{\mathrm{b}}$ & Acetaldehyde $^{\mathrm{b}}$ & $\begin{array}{l}\text { Ethyl } \\
\text { acetate }^{\mathrm{b}}\end{array}$ & $\begin{array}{c}1- \\
\text { propanol }^{\mathrm{b}}\end{array}$ & $\begin{array}{c}1- \\
\text { butanol }^{\mathrm{b}, \mathrm{c}}\end{array}$ & $\begin{array}{c}2- \\
\text { butanol }^{\mathrm{b}}\end{array}$ & Isobutanol $^{\mathrm{b}}$ & $\begin{array}{l}\text { Isoamyl } \\
\text { alcohol }^{\text {b }}\end{array}$ & $\begin{array}{c}1- \\
\text { hexanol }^{\mathrm{b}, \mathrm{c}}\end{array}$ & $\begin{array}{c}\text { Sum of higher } \\
\text { alcohols }\end{array}$ \\
\hline 43 & 50.3 & 0.9 & 13.3 & 7.6 & 14.1 & 0.1 & 19.2 & 4.3 & 9.9 & 0.5 & 48.2 \\
\hline 44 & 50.2 & 1.2 & 10.8 & 18.3 & 29.3 & 0.1 & 9.7 & 4.4 & 9.2 & 0.7 & 53.5 \\
\hline 45 & 47.0 & 0.4 & 10.7 & 27.4 & 42.7 & 0.1 & 11.1 & 4.3 & 9.1 & 0.5 & 67.8 \\
\hline 46 & 42.8 & 0.5 & 34.1 & 17.2 & 48.0 & 0.6 & 1.8 & 0.7 & 2.2 & 0.6 & 53.9 \\
\hline 47 & 42.0 & 0.4 & 21.3 & 18.3 & 43.2 & 0.3 & 0.7 & 0.5 & 1.2 & 0.9 & 46.9 \\
\hline
\end{tabular}

\begin{tabular}{|c|c|c|c|c|}
\hline \multirow[b]{2}{*}{ Sample } & \multirow{2}{*}{$\begin{array}{c}\text { Ethanol } \\
\text { (ABV\%) }\end{array}$} & \multicolumn{3}{|c|}{$\mu \mathrm{g} / \mathrm{L}$} \\
\hline & & Arsenic $^{\mathrm{d}}$ & Cadmium $^{\mathrm{d}}$ & Lead $^{\mathrm{d}}$ \\
\hline 1 & 63.7 & n.d. & 0.30 & n.d. \\
\hline 2 & 52.9 & n.d. & n.d. & n.d. \\
\hline 3 & 47.6 & n.d. & n.d. & n.d. \\
\hline 4 & 59.7 & 0.22 & n.d. & n.d. \\
\hline 5 & 47.6 & n.d. & 0.95 & n.d. \\
\hline 6 & 49.6 & n.d. & 19.55 & 580.00 \\
\hline 7 & 57.4 & n.d. & n.d. & n.d. \\
\hline 8 & 54.2 & 0.93 & n.d. & n.d. \\
\hline 9 & 56.3 & 0.97 & 0.70 & n.d. \\
\hline 10 & 51.0 & n.d. & 6.15 & 81.20 \\
\hline 11 & 48.7 & 0.65 & 9.20 & 176.25 \\
\hline 12 & 51.1 & 4.55 & 5.6 & 76.55 \\
\hline 13 & 50.4 & 2.65 & 5.55 & 63.40 \\
\hline 14 & 52.8 & 0.00 & 4.35 & 55.00 \\
\hline 15 & 48.9 & 2.15 & 9.35 & 134.60 \\
\hline 16 & 49.7 & 1.00 & 5.65 & 79.55 \\
\hline 17 & 38.7 & n.d. & 6.15 & 79.55 \\
\hline 18 & 51.2 & 1.25 & 6.10 & 100.70 \\
\hline 19 & 48.2 & 10.15 & 6.60 & 81.85 \\
\hline 20 & 49.2 & n.d. & 19.00 & 178.00 \\
\hline 21 & 50.4 & n.d. & 5.35 & 81.05 \\
\hline 22 & 53.7 & n.d. & 4.35 & 68.60 \\
\hline 23 & 49.4 & n.d. & 2.60 & 24.85 \\
\hline 24 & 48.3 & n.d. & 1.95 & 21.25 \\
\hline 25 & 49.6 & n.d. & 1.75 & 25.50 \\
\hline 26 & 54.0 & 3.55 & 3.90 & 36.10 \\
\hline 27 & 52.8 & n.d. & 1.40 & 21.55 \\
\hline 28 & 46.2 & n.d. & 1.50 & n.d. \\
\hline 29 & 53.5 & n.d. & 0.60 & n.d. \\
\hline 30 & 50.5 & 0.30 & 0.80 & n.d. \\
\hline 31 & 52.7 & n.d. & 1.45 & 0.60 \\
\hline 32 & 49.8 & 0.85 & 1.15 & n.d. \\
\hline 33 & 49.0 & n.d. & 1.10 & n.d. \\
\hline 34 & 49.0 & n.d. & 0.75 & n.d. \\
\hline 35 & 47.9 & n.d. & 1.00 & n.d. \\
\hline 36 & 50.5 & 10.15 & 0.80 & n.d. \\
\hline 37 & 44.4 & 0.35 & 0.80 & n.d. \\
\hline
\end{tabular}




\begin{tabular}{ccccc}
\hline & $\begin{array}{c}\text { Ethanol } \\
\text { Sample }\end{array}$ & \multicolumn{3}{c}{$\mu / \mathrm{L}$} \\
\cline { 3 - 5 } (ABV\%) & Arsenic $^{\mathrm{d}}$ & Cadmium $^{\mathrm{d}}$ & Lead $^{\mathrm{d}}$ \\
\hline 38 & 51.3 & n.d. & 1.05 & n.d. \\
39 & 56.2 & 1.85 & 0.90 & n.d. \\
40 & 49.6 & 5.20 & 1.10 & 4.75 \\
41 & 48.3 & n.d. & 1.25 & 4.25 \\
42 & 50.9 & 4.00 & 1.80 & 2.55 \\
43 & 50.3 & n.d. & 0.75 & 0.00 \\
44 & 50.2 & 2.20 & 1.65 & 6.70 \\
45 & 47.0 & 2.55 & 1.00 & 9.85 \\
46 & 42.8 & 15.70 & 1.30 & 4.80 \\
47 & 42.0 & 6.05 & 1.70 & 0.35 \\
\hline
\end{tabular}

${ }^{\text {a }}$ Concentration of volatile compounds was obtained in $\mathrm{mg} / \mathrm{L}$ and converted to $\mathrm{g} / \mathrm{hl}$ pa by multiplying the obtained value by factor of $10 / \mathrm{alcoholic}$ strength (ABV) for each sample

${ }^{\mathrm{b}}$ Detection limit: $10^{-3} \mathrm{mg} / \mathrm{L}$ for volatile compounds (higher alcohol, methanol, acetaldehyde, and ethyl acetate)

${ }^{c}$ Values of $\leq 0.05$ are reported as 0.(0 1-butanol and 1-hexanol were detected in all samples)

${ }^{\mathrm{d}}$ n.d. indicates not detected. Detection limit: $10^{-2} \mu \mathrm{g} / \mathrm{L}$ for non-volatile elements (Ar, Cd, and $\mathrm{Pb}$ )

To accurately report the small amounts of heavy metals detected in our analysis, we report the $\mu \mathrm{g} / \mathrm{L}$ rather than $\mathrm{mg} / \mathrm{L}$. Arsenic was detected in 22 (46.8\%) of our samples with the concentration ranging up to $15.70 \mu \mathrm{g} / \mathrm{L}$. Cadmium was detected in 42 (89.4\%) of our samples, with a maximum concentration of $19.55 \mu \mathrm{g} / \mathrm{L}$. Lead was detected in 27 (57.4\%) of our samples. The highest concentration of lead was $580 \mu \mathrm{g} / \mathrm{L}$, found in sample 6 .

\section{Discussion}

In this section we first discuss the results of the chemical analysis and then the public health implications of these results.

Ethanol is a central nervous system depressant, and with chronic use is associated with more than 50 disease conditions (Rehm et al., 2009; Shield, Parry, \& Rehm, 2013). The typical strength of commercially distilled spirits is around $40 \% \mathrm{ABV}$. Unrecorded alcohols are assumed to have higher $\mathrm{ABV}$ than recorded alcohol (Rehm et al., 2010). Rehm et al. (2010) suggested that the principal contribution to public health risk from unrecorded alcohol is the ethanol concentration, although the risk from ethanol may be moderated by patterns of use (Rehm et al., 2003; Rehm et al., 2009; WHO, 2014). The samples of unrecorded bai jiu analyzed for this paper ranged from $38.7 \%$ to $63.7 \% \mathrm{ABV}$, with a mean of $50.4 \% \mathrm{ABV}$. For comparison, Lachenmeier, Monakhova, Rehm, Kuballa, and Straub (2013) reported a range of $44.5 \%$ to $62.1 \%$ $\mathrm{ABV}$, with a mean of $54.7 \% \mathrm{ABV}$, in 25 samples of Chinese commercial spirits purchased in Asian markets and restaurants in Baden-Württemberg, Germany, and Toronto, Canada. Both our study and Lachenmeier et al.'s (2013) examined very small samples, but the ethanol concentrations of the unrecorded bai jiu samples we tested are comparable to what was found in the recorded alcohol samples in Lachenmeier et al. We could find no reports of
ABVs of recorded and unrecorded spirits from shops in China with which to compare our result. More study is needed, especially in China where there is little actual data on any aspect of unrecorded alcohol.

Ingestion of methanol, also known as methyl alcohol or wood alcohol, is toxic to humans because it is a central nervous system depressant (Bitar, Ashebu, \& Ahmed, 2004), and the product of its metabolism is toxic. Methanol is converted to formaldehyde via alcohol dehydrogenase, and formaldehyde is then converted to formic acid via aldehyde dehydrogenase. Formic acid damages the nervous system, especially the optic nerve, and in the process of its metabolism also damages the liver and the kidneys (International Programme on Chemical Safety, 1997). The usual source of methanol in fermentation is pectin, present in ripe fruits (Sakai, Sakamoto, Hallaert, \& Vandamme, 1993). The bai jiu samples we collected and tested were made from grains, which are naturally low in pectin. This likely explains the low levels of methanol in our samples. No samples exceeded the limit of $1000 \mathrm{~g} / \mathrm{hl}$ suggested by AMPHORA for unrecorded alcohol (Lachenmeier et al., 2011).

Acetaldehyde is also a natural byproduct of fermentation. It forms early in fermentation when its concentration is highest, and as fermentation proceeds, its concentration decreases as some is reabsorbed by the yeast (Lachenmeier \& Sohnius, 2008). Acetaldehyde is toxic, carcinogenic, mutagenic, and might be a contributor to alcohol dependence (International Agency for Research on Cancer, 1999; Lachenmeier, Kantares, \& Rehm, 2009; Zakhari, 2006). Three of our 47 samples had concentrations of acetaldehyde higher than the $50 \mathrm{~g} / \mathrm{hl}$ pa limit set by AMPHORA for unrecorded alcohol (the three samples were $54.4 \mathrm{~g}, 55.9 \mathrm{~g}$, and $59.5 \mathrm{~g}$ acetaldehyde/hl pa). The variability in levels across the different samples is likely a result of the practices of the individual alcohol maker, such as the time allowed for initial grain fermentation and how 
much of the first distillate is blended back into the final product. Blending back the first distillate is often done to satisfy taste expectations. Ambient air temperature during fermentation and the type and quantity of yeast could also contribute to acetaldehyde variability.

Ethyl acetate is the most common ester found in beverage alcohols. At low levels, it is responsible for fragrance and fruity odor, and at higher levels, for the sharp vinegary taste sometimes associated with spoilage (Osobamiro, 2013). The AMPHORA project has set $1,000 \mathrm{~g} / \mathrm{hl}$ pa as the upper limit for ethyl acetate in unrecorded alcohol. All samples tested below this limit.

Higher alcohols or fusel alcohols are natural byproducts of alcohol fermentation by yeast and are important flavor compounds. Higher alcohols have effects similar to ethanol, and potency might increase with chain length (Lachenmeier, Haupt, \& Schulz, 2008; Rehm et al., 2010). Few studies have linked the toxicity of unrecorded alcohol to the presence of higher alcohols (Lachenmeier, Rehm, \& Gmel, 2007; McKee et al., 2005). A maximum level of $1000 \mathrm{~g} / \mathrm{hl}$ pa for the sum of all possible detectable higher alcohols has been set by the AMPHORA. The sum of higher alcohols in this study refers to the sum of the six higher alcohols analyzed: 1-propanol, 1-butanol, 2-butanol, isobutanol, isoamyl alcohol, and 1-hexanol. In none of our samples did the sum of the six higher alcohols exceed the limit set by AMPHORA. However, our samples could have higher levels had we tested for a wider range of higher alcohols. We tested for these six because they are the most common in beverage alcohols.

The presence of non-volatile metal components, especially heavy metals, can be carcinogenic and toxic (Jarup, 2003). Heavy metals enter unrecorded alcohol through the equipment used in distillation, the vessels used for storage, substances like dilution water added during production, or from the soil in which the grains were grown (Ibanez, Carreon-Alvarez, Barcena-Soto, \& Casillas, 2008). Low doses of arsenic over time produce chronic effects to the skin, peripheral nerves, cardiovascular system, and central nervous system, and they increase the likelihood of a range of cancers (Jarup, 2003). Arsenic was detected in 22 (46.8\%) of our samples with concentrations ranging up to $15.70 \mu \mathrm{g} / \mathrm{L}$; these concentrations are below the $100 \mu \mathrm{g} / \mathrm{L}$ limit set by AMPHORA. Cadmium is poisonous, and exposure is a risk factor for early atherosclerosis (Messner et al., 2009) and hypertension (Houston, 2007). The maximum limit for cadmium set by the AMPHORA for unrecorded alcohol is $10 \mu \mathrm{g} / \mathrm{L}$. Cadmium was detected in $42(89.4 \%)$ of the samples, with 2 samples exceeding the AMPHORA limit. At certain levels lead damages the central nervous system and brain, causes blood disorders (Jarup, 2003), and accumulates in both soft tissue and the bones (Barry, 1975). The maximum limit for lead in unrecorded alcohol set by AMPHORA is $200 \mu \mathrm{g} / \mathrm{L}$ (Lachenmeier et al., 2011). Twenty (42.6\%) of our 47 samples recorded no detectable lead, and 26 samples (55.3\%) recorded lead levels below $200 \mu \mathrm{g} / \mathrm{L}$. One sample exceeded the AMPHORA limit.

\section{Public Health Implications}

From the small sample we analyzed we found no evidence of contamination or adulteration, nor did we expect to. The occurrence of contamination and adulteration that could result in death, while concerning, is relatively rare, contributing to less than $1 \%$ of alcohol attributed deaths (Rehm et al., 2014).

Rarely mentioned as a danger from unrecorded alcohol is the possible chronic effect from low levels of toxic chemicals. In this project, three samples exceeded AMPHORA standards for heavy metals: two samples that contained cadmium $(19.55 \mu \mathrm{g} / \mathrm{L}$ and $19.00 \mu \mathrm{g} / \mathrm{L})$ and one that contained lead $(580 \mu \mathrm{g} / \mathrm{L})$. If the cadmium and lead consistently occurred in the same alcohol from the same producer and this producer had a stable customer base, then there would be the possibility of chronic effects for these customers. Both cadmium and lead enter the alcohol beverage through many routes, some of which may be exacerbated by the introduction of other technologies, such as the use of fertilizers to increase grain production. If locally made alcohol contains heavy metals, then it is likely in other foods, also.

Unrecorded alcohols are assumed to have higher ABV than recorded alcohol (Rehm et al., 2010). The average ABV of the unrecorded bai jiu samples analyzed in this study was comparable to the average $\mathrm{ABV}$ of commercial Chinese spirits samples analyzed by Lachenmeier et al. (2013). The high ethanol content of these locally distilled unrecorded spirits appears to be the main health concern-the same health concern as with recorded, commercially produced spirits.

The World Health Organization (WHO, 2010) recognizes the cultural significance of "informally" produced alcohol and acknowledges that its use is also often "informally" controlled in ways that reduce risks. Cultural significance is evident in the role that unrecorded alcohol plays in daily diet, special ceremonies, and rites of passage. There are other less visible contributions of unrecorded alcohol. For example, Luu, Nguyen, and Newman (2014) and Qian et al. (2015) describe the contribution that informal alcohol production and sale can make to the economic welfare of rural families. They also describe an example of an informal control in their description of sales networks in which the maker and the seller know their customers and therefore are unlikely to intentionally do anything to their beverage that could endanger their customers' health or the alcohol makers' reputation. These makers follow a tradition of skills that have been handed down from generation to generation without any knowledge of chemistry or any sophisticated instrumentation to monitor the quality of their product, yet they produce a product that is generally safe and respected in the community. However, there is no way that these informal controls would protect drinkers from any chronic cumulative effects from high levels of lead and cadmium as identified in three of our samples.

It is worth noting that much of the evidence suggesting risks associated with unrecorded or traditional alcohol 
comes from European countries and to a lesser degree from Africa and the Americas. With the exception of a few small studies in Asia-Vietnam (Lachenmeier, Anh, Popova, \& Rehm, 2009; Luu et al., 2014), Sikkim (Chakrabarti, Rai, Sharma, \& Rai, 2014), Sri Lanka (Liyanage, 2008), and China (Qian et al., 2015) — there is little reported about the production and use of unrecorded bai jiu, or about the chemical content of artisanal alcohol from the countries of Asia. Increased knowledge of all aspects of unrecorded alcohol production, use, and composition, especially from China, would be useful for developing policies to reduce alcohol-related risks.

\section{Conclusions and Implications}

These findings, though limited to one geographic area and to a small number of samples, present the results of one of the first reported chemical analyses of samples of unrecorded bai jiu from central China. We have no comparable data from other samples of unrecorded alcohol for comparison.

Five of the 47 samples analyzed suggested increased risk to consumers from the chemicals we analyzed. Rehm and colleagues (2014), after reviewing research on unrecorded alcohol, have concluded that there is little evidence to suggest that consumption of unrecorded traditional alcohol is significantly linked to patterns of population mortality or morbidity over and above the level of ethanol. Our data do not challenge this conclusion.

\section{Limitations}

The small number of samples analyzed and the limited geographic region from which the samples were collected limit any generalizations from these findings. Nevertheless, they do provide a first look at the chemical composition of unrecorded alcohol from this region of China and do suggest opportunities to better understand ethanol levels and the presence of chemicals that may have chronic effects at relatively low concentrations.

\section{Acknowledgements}

The authors acknowledge the assistance of Michelle Maas in editing this paper.

\section{References}

Barry, P. S. I. (1975). A comparison of concentrations of lead in human tissues. British Journal of Industrial Medicine, 32(2), 119-139.

Bitar, Z. I., Ashebu, S. D., \& Ahmed, S. (2004). Methanol poisoning: Diagnosis and treatment. A case report. International Journal of Clinical Practice, 58, 1042 1044. doi:10.1111/j.1368-5031.2004.00034.x

Chakrabarti, A., Rai, T. K., Sharma, B., \& Rai, B. B. (2014). Culturally prevalent unrecorded alcohol consumption in Sikkim, North East India: Crosssectional situation assessment. Journal of Substance
Use, 20(3), 162-167. doi:10.3109/14659891.2014. 885598

Houston, M. C. (2007). The role of mercury and cadmium heavy metals in vascular disease, hypertension, coronary heart disease, and myocardial infraction. Alternative Therapies in Health and Medicine, 13, S128-S133.

Ibanez, J. G., Carreon-Alvarez, A., Barcena-Soto, M., \& Casillas, N. (2008). Metals in alcoholic beverages: A review of sources, effects, concentrations, removal, speciation, and analysis. Journal of Food Composition and Analysis, 21(8), 672-683. doi:10.1016/ j.jfca.2008.06.005

International Agency for Research on Cancer. (1999). Acetaldehyde. Re-evaluation of some organic chemicals, hydrazine and hydrogen peroxide. IARC Monographs on the Evaluation on the Carcinogenic Risks to Humans, 71, 319-335.

International Programme on Chemical Safety. (1997). Methanol. Environmental Health Criteria 196. Geneva, Switzerland: World Health Organization. Retrieved from http://www.inchem.org/documents/ ehc/ehc/ehc196.htm

Jarup, L. (2003). Hazards of heavy metal contamination. British Medical Bulletin, 68(1), 167-182. doi:10.1093/bmb/ldg032

Lachenmeier, D. W., Anh, P. T. H., Popova, S., \& Rehm, J. (2009). The quality of alcohol products in Vietnam and its implications for public health. International Journal of Environmental Research and Public Health, 6(8), 2090-2101. doi:10.3390/ijerph6082090

Lachenmeier, D. W., Haupt, S., \& Schulz, K. (2008). Defining maximum levels of higher alcohols in alcoholic beverages and surrogate alcohol products. Regulatory Toxicology and Pharmacology, 50(3), 313-321.

Lachenmeier, D. W., Kanteres, F., \& Rehm, J. (2009). Carcinogenicity of acetaldehyde in alcoholic beverages: Risk assessment outside ethanol metabolism. Addiction, 104(4), 533-550. doi:10.1111/j.1360-0443.2009.02516.x

Lachenmeier, D. W., Monakhova, Y. B., Rehm, J., Kuballa, T., \& Straub, I. (2013). Occurrence of carcinogenic aldehydes in alcoholic beverages from Asia. The International Journal of Alcohol and Drug Research, 2(2), 31-36.

Lachenmeier, D. W., Rehm, J., \& Gmel, G. (2007). Surrogate alcohol: What do we know and where do we go? Alcoholism: Clinical and Experimental Research, 31(10), 1613-1624. doi:10.1111/j.15300277.2007.00474.x

Lachenmeier, D. W., Sarsh, B., \& Rehm, J. (2009). The composition of alcohol products from markets in Lithuania and Hungary, and potential health consequences: A pilot study. Alcohol and Alcoholism, 44(1), 93-102. doi:10.1093/alcalc/agn095

Lachenmeier, D. W., Schoeberl, K., Kanteres, F., Kuballa, T., Sohnius, E. M., \& Rehm, J. (2011). Is contaminated unrecorded alcohol a health problem in the European Union? A review of existing and methodological outline for future studies. Addiction, 
106(Suppl.1), 20-30. doi:10.1111/j.13600443.2010.03322.x

Lachenmeier, D. W., \& Sohnius, E. M. (2008). The role of acetaldehyde outside ethanol metabolism in the carcinogenicity of alcoholic beverages: Evidence from a large chemical survey. Food and Chemical Toxicology, 46(8), 2903-2911. doi:10.1016/S01406736(09)60746-7

Liyanage, U. (2008). Noncommercial alcohol in Southern Asia: The case of kasippu in Sri Lanka. In ICAP review 3: Noncommercial alcohol in three regions (pp. 24-34). Washington, DC: International Center for Alcohol Policies.

Luu, B. N., Nguyen, T. T., \& Newman, I. M. (2014). Traditional alcohol production and use in three provinces in Vietnam: An ethnographic exploration of health benefits and risks. BMC Public Health, 14, 731. doi:10.1186/1471-2458-14-731

McKee, M., Suzcs, S., Sarvary, A., Adany, R., Kiryanov, N., Saburova, L., . . . Leon, D. A. (2005). The composition of surrogate alcohols consumed in Russia. Alcoholism: Clinical and Experimental Research, 29(10), 1884-1888. doi:10.1097/01.alc.0000183012.93303.90

Messner, B., Knoflach, M., Seubert, A., Ritsch, A., Pfaller, K., Henderson, B., . . . Bernhard, D. (2009). Cadmium is a novel and independent risk factor for early atherosclerosis mechanisms and in vivo relevance. Arteriosclerosis Thrombosis and Vascular Biology, 29(9), 1392-1398. doi:10.1161/ATVBAHA.109. 190082

Osobamiro, T. (2013). Analysis of some contaminants commonly found in alcoholic beverages. AmericanEurasian Journal of Scientific Research, 8(1), 53-56. doi:10.5829/idosi.aejsr.2013.8.1.6453

Qian, L., Newman, I. M., Xiong, W., \& Feng, Y. (2015). Traditional grain alcohol (bai jiu, 白酒) production and use in rural central China: Implications for public health. BMC Public Health, 15(1), 1.

Rehm, J., Kailasapillai, S., Larsen, E., Rehm, J. X., Samokhvalov, A. V., Shield, K. D., . . . Lachenmeier, D. W. (2014). A systematic review of the epidemiology of unrecorded alcohol consumption and the chemical composition of unrecorded alcohol. Addiction, 109(6), 880-893. doi:10.1111/add.12498

Rehm, J., Kanteres, F., \& Lachenmeier, D. W. (2010). Unrecorded consumption, quality of alcohol and health consequences. Drug and Alcohol Review, 29, 426-436. doi:10.111/j.1465-3362.2009.00140.x

Rehm, J., Mathers, C., Popova, S., Thavorncharoensap, M., Teerawattananon, Y., \& Patra, J. (2009). Global burden of disease and injury and economic cost attributable to alcohol use and alcohol-use disorders. Lancet, 373, 2223-2233. doi:10.1016/S01406736(09)60746-7

Rehm, J., Rehn, N., Room, R., Monteiro, M., Gmel, G., Jernigan, D., \& Frick, U. (2003). The global distribution of average alcohol consumption and patterns of drinking. European Addiction Research, 9, 147-156. doi:10.1159/000072221

Sakai, T., Sakamoto, T., Hallaert, J., \& Vandamme, E. J. (1993). Pectin, pectinase and protopectinase: Production, properties, and applications. Advances in Applied Microbiology, 39, 213-294.

Shield, K. D., Parry, C., \& Rehm, J. (2013). Chronic diseases and conditions related to alcohol use. Alcohol Research: Current Reviews, 35(2), 155-171. Retrieved from http://pubs.niaaa.nih.gov/publications/ arcr352/155-173.htm

Tang, Y., Xiang, X., Wang, X., Cubells, J. F., Babor, T. F., \& Hao, W. (2013). Alcohol and alcohol-related harm in China: Policy changes needed. Bulletin of the World Health Organization, 91(4), 270-276. doi:10.2471/BLT.12.107318

World Health Organization. (2010). Global strategy to reduce the harmful use of alcohol. Geneva, Switzerland: World Health Organization.

World Health Organization. (2014). Global status report on alcohol and health 2014. Retrieved from http://www.who.int/substance_abuse/publications/glob al_alcohol_report/en/

Zakhari, S. (2006). Overview: How is alcohol metabolized by the body? Alcohol Research and Health, 29(4), 245-254.

\section{Appendix A}

\section{Description of methods used in the analysis}

\section{Determination of volatile organic compounds}

Gas chromatography was used to determine the concentrations of volatile organic compounds: ethanol, methanol, acetaldehyde, ethyl acetate, and higher alcohols. The test for each sample was recorded in mg/L, and converted to g/hl of pure alcohol (pa) by multiplying the recorded value by the factor of 10/ethanol concentration (ABV). The apparatus consisted of Shimadzu GC-2010, PE Turbomatrix 16 (head space sampler), flame ionization detector, and OV1701 column. The operating conditions were: injector temperature, $160{ }^{\circ} \mathrm{C}$; detector temperature, $260{ }^{\circ} \mathrm{C}$; column temperature, $40{ }^{\circ} \mathrm{C}(3 \mathrm{~min})-180^{\circ} \mathrm{C}(2 \mathrm{~min}) / 10^{\circ} \mathrm{C}$; carrier gas, $\mathrm{N}_{2}, 23 \mathrm{kPa}$; flow rate, $5 \mathrm{ml} / \mathrm{min}$; air flow rate, $400 \mathrm{ml} / \mathrm{min} ; \mathrm{H}_{2}$ flow rate, $47 \mathrm{ml} / \mathrm{min}$; make up gas, $30 \mathrm{ml} / \mathrm{min}$; head space conditions, vial temperature: $70{ }^{\circ} \mathrm{C}$; thermosetting time, $25 \mathrm{~min}$; pressurization time, $25 \mathrm{~min}$; transfer line temperature, $130{ }^{\circ} \mathrm{C}$.

\section{Determination of heavy metals}

Samples were tested for three heavy metals: cadmium (Cd), arsenic (As), and lead (Pb). SpectraAA 220/220Z Graphite Furnace Atomic Absorption Spectroscopy (Varian) consisting of element hollow cathode lamp (Vigorous) was used to determine the 
concentration of these metals, which are reported in units of $\mu \mathrm{g} / \mathrm{L}$. Reagents used in the analytical process were nitric acid, hydrochloric acid, high chlorine acid (guarantee reagent), and ultra-pure experimental water. For the standard reserve liquids, the concentrations of $\mathrm{As}, \mathrm{Pb}$, and $\mathrm{Cd}$ were $1000 \mu \mathrm{g} / \mathrm{L}$ respectively for each element and were purchased from national chemical reagent quality inspection center. For the standard application liquid, the concentration was $20 \mathrm{ng} / \mathrm{ml} \mathrm{for} \mathrm{As,} 20 \mathrm{ng} / \mathrm{ml} \mathrm{for} \mathrm{Pb}$, and $2 \mathrm{ng} / \mathrm{ml}$ for Cd. The reserve liquid was diluted with $5 \% \mathrm{HCl}(\mathrm{v} / \mathrm{v})$ to different concentration. The instrument was adjusted to different working condition to determine a particular metal concentration as illustrated in the Appendix Table 1.

For the purpose of quantitative analysis of heavy metals, spirit samples were digested first. For this, 200 ml of spirit sample was placed in the beaker, which was heated to remove alcohol and water from the sample. The heating was stopped when the volume of sample reached $2 \mathrm{ml}$. Transfer of the residual spirit to the flask was followed by the addition of $2 \mathrm{ml}$ nitric acid $\left(\mathrm{HNO}_{3}\right)$ and $0.5 \mathrm{ml}$ of perchloric acid $\left(\mathrm{HClO}_{4}\right)$. The mixture was heated until the clear liquid was obtained or the volume of the mixture was $0.5 \mathrm{ml}$. The ultrapure water was added to the digested sample to reach the $25 \mathrm{ml}$ mark in the flask. Then, approximately 1 to 2 $\mathrm{ml}$ of the digested sample was acidified using $5 \% \mathrm{HCl}$ and placed in the reactor of the instrument to calculate the concentration of heavy metals.

\section{Appendix Table 1}

Working conditions for graphite furnace atomic absorption spectroscopy

\begin{tabular}{lcccc}
\hline Element & Wavelength Spectral (nm) & Width $(\mathbf{n m})$ & Lamp current $(\mathbf{m A})$ & Atomization temperature $\left.\mathbf{(}^{\mathbf{0}} \mathbf{C}\right)$ \\
\hline $\mathrm{As}$ & 193.7 & 0.5 & 6 & 2300 \\
$\mathrm{~Pb}$ & 283.3 & 0.5 & 2 & 2100 \\
$\mathrm{Cd}$ & 228.8 & 0.5 & 3 & 1800 \\
\hline
\end{tabular}

\section{Determination of Alcohol by Volume Percent (ABV \%)}

Concentration of ethanol is reported in percentage alcohol by volume (ABV \%). Alcohol strength was determined by oenometer (alcoholometer). A $100 \mathrm{ml}$ spirit sample was transferred into a $500 \mathrm{ml}$ distillation flask with $100 \mathrm{ml}$ of distilled deionized water. The solution was distilled by electric stove, and the distillate was collected into a 100-ml volumetric flask, which was dipped into ice water. Distillation was stopped when distillate approached the 100-ml mark. The oenometer was placed in the collected distillate and was allowed to float. The mark at which the spirit level crossed the stem of the instrument was recorded, and the concentration of alcohol or ethanol in sample was calculated according to temperature. 